\title{
The Effectiveness of ReengineeringMohebProject to Improve Knowledge, Attitude, and Performance of Individuals \& Local Communities in Response to Earthquake: A Case Study
}

Hamidreza Eskash ${ }^{1}$, Morteza Moradipour ${ }^{2}$, Mina Nazari Kamal ${ }^{3 *}$, Sheida Sarafzadeh ${ }^{4}$, Mahboobeh Rouhollahi ${ }^{5}$, Abdolreza Arghaii $^{6}$, Rahele Samouei $^{7}$

1. Iran Helal Institute of Applied Science \& Technology, Tehran, Iran.

2. Deputy for Relief \& Rescue, Red Crescent Society of the Islamic Republic of Iran, Tehran Provincial Branch, Tehran, Iran.

3. Department of Psychology, Faculty of Literature and Humanities, University of Guilan, Rasht, Iran.

4. Department of Biostatistics, School of Public Health, Isfahan University of Medical Sciences, Isfahan, Iran.

5. Department of Natural Disaster Management, Faculty of Environment, University of Tehran, Tehran, Iran.

6. Rescue Organization, Red Crescent Society of the Islamic Republic of Iran, Tehran, Iran.

7. Department of Health Management in Disaster, Social Determinants of Health Research Center, Isfahan University of Medical Sciences, Isfahan, Iran.

Cttation: Eskash HR, Moradipour M, Nazari Kamal M, Sarafzadeh Sh, Rouhollahi M, Arghaii AR, et al. The Effectiveness of Reengineering Moheb Project to Improve Knowledge, Attitude, and Performance of Individuals and Local Communities in Response to Earthquake: A Case Study. Health in Emergencies and Disasters Quarterly. 2016; 1(4):193-199. https://doi.org/10.18869/nrip.hdq.1.4.193

: https://doi.org/10.18869/nrip.hdq.1.4.193

Article info:

Received: 01 Mar. 2016

Accepted: 02 Jun. 2016

\section{Keywords:}

Reengineering, Moheb project, Knowledge, Attitude, Performance, Preparedness, Disaster

\section{A B S T RACT}

Background: Evaluating the effectiveness of reengineering Moheb (interventions and sociopsychological supports in disasters) project helps the managers of the Welfare Organization have feedback on the status of community empowerment against disasters. In this regard, this study aimed to determine the effectiveness of reengineering Moheb project to improve the knowledge, attitude, and performance of individuals and local communities in respond to earthquake.

Materials and Methods: This quasi-experimental study with two groups of control and case was conducted in Iran, in 2013. Hormozgan, Isfahan, Fars, and South Khorasan provinces were selected as the setting for the case group and Tehran, Markazi, Semnan, and Khorasan Razavi provinces were selected as the setting for the control group. A total number of 399 samples were assessed using questionnaires of evaluating effectiveness of Moheb project $(\mathrm{a}=0.704)$ and checklist of empowerment preparedness of local people. The assessed data were analyzed through independent $\mathrm{t}$ test, analysis of variance, Chi-square, Mann-Whitney, and Kruskal-Wallis tests by using SPSS 20.

Results: Based on the results, the proceedings done in the reengineering Moheb project, including organizing local disaster management teams, briefing/training sessions, as well as executed maneuvers have been instrumental in all subscales, i.e. participants of case provinces compared to participants of control provinces were better with regard to knowledge, attitude, and performance.

Conclusion: Regarding the fact that knowledge, attitude, and performance of the people at local communities about earthquake were improved, the interventional programs, especially educational and promotional plan, can effectively empower individuals to face disasters.

\footnotetext{
* Corresponding Author:

Mina Nazari Kamal, MSc.

Address: Department of Psychology, Faculty of Literature and Humanities, University of Guilan, Rasht, Iran

E-mail:mnkamalabadi@gmail.com
} 


\section{Introduction}

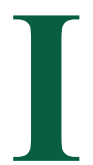

$\mathrm{n}$ every society, social preparedness is the main prerequisite in response to destructive outcomes of man-made or natural disasters [1]. This program is able to increase individual and social endurance and decrease the economic damages and the duration of reconstruction period [2]. Based on this fact and as a management approach, participation of people in crisis management can result in identification of the threats with cooperation of the locals. Then, by asking the influential and active people in the society to act and play a part in all levels of crisis management cycle, required conditions are provided for empowering local individuals and groups to face the crisis $[3,4]$.

Because applying this approach in different countries is totally affected by cultural, social, economic, political, and health specifications and conditions of the region, it is impossible to present a single approach for its institutionalizing in every society. Therefore, training and organizing local societies in the face of man-made or natural disasters should be subjected to specific conditions of that country, region, village, or area in which the program is applied [2]. In this regard, different models were presented in society-based management, all over the world $[5,6]$. Our country is not an exception, and different programs were presented in society-based management. Moheb project (interventions and sociopsychological supports in disasters) was presented by National Welfare Organization which was subjected to reengineering1 through 2010 to 2012.

Today, training and preparing local societies is one of the main strategies of governments to cope with dangerous situations $[8,9]$. These trainings aim to enable the locals to face earthquake through improving their knowledge, attitude, and individual and social preparedness. To this aim, precise and scientific analyses is required to determine the degree of achievement and gain a holistic view of the effectiveness of the measures carried out [9]. Since, training analysis is an approach in gathering information, it helps the managers to make valuable decisions with regard to training programs $[9,10]$. Thus, reviewing the activities done by a program, with the aim of managing massive disasters, would need the analysis

1. The reason for reengineering the program was to improve its constructional framework from traditional model to international IMS/ ICS/RRT/CERT model, which was domesticized and localized, in other words, standardized with regards to organizational and social conditions in Iran. methods suitable with those performed activities. This method is considered important by most countries in the world, as the base of future training programs in the face of natural disasters [6]. For example, India [11, 12], Bangladesh [13], and Nepal [14] compared the performance and the amount of damages and casualties in villages that have gone through the necessary trainings with those of the control villages. These studies showed the effectiveness of these interventions on the improvement of preparedness of local people, lower economic and life casualties, and more endurance in trained villages in the face of natural disasters. Analyzing social-based crisis trainings in Pakistan [15] and Vietnam showed that the knowledge, attitude, and performance of different societies, especially women and children have changed because of this program [16].

In fact, one of the requirements of any social preparedness program in the face of dangers is to analyze the effectiveness of the program and its coordination with social context in every region [17]. Such an analysis of emergency situation would provide the managers in Welfare Organization and other institutions active in the field of crisis management with the means to determine the positive and negative outcomes of their decisions and through this, they reinforce the effectiveness of their activities and empower the local forces in crisis [18]. Therefore, the main question in this research is whether reengineering Moheb project has been effective in increasing the knowledge, attitude, and performance of local individuals and groups

\section{Materials and Methods}

The research design is quasi-experimental with case/ control groups. It was carried out in 9 months from September 2013 to June 2014, and the field analysis was conducted between November 2013 and April 2014. Statistical population comprised all people in the country. In the next step, two groups of provinces were separated based on the implementing or the lack of implementing the Moheb project in them. In this regard, case group involved neighborhoods and villages (local communities) in the provinces which participated in reengineering Moheb project between 2010 and 2012. Control group consisted of all local communities of the provinces which did not participate in Moheb project and its reengineering.

The samples in the first group consisted of 4 provinces of Hormozgan, Isfahan, Fars, and South Khorasan in which the Moheb project maneuver was performed in their selected local communities i.e. neighborhoods and villages (Golshahr and Lathar neighborhoods, Fathabad village, and Rahmatabad neighberhood in a consecutive 
order) in 2012. Samples in the control group were selected from 4 provinces of Tehran, Markazi, Khorasan Razavi, and Semnan. The local people were recruited from Amrabad and Kohanabad neighborhoods, Marandiz village and Ali-ibn-Abitaleb Mosque neighborhoods in which the program was not implemented.

The local communities in the control group were selected based on their similarities in climate and cultural preferences to the local communities in the case group. The research sampling in was done by convenience sampling method.

The participants in trainings and maneuvers of reengineered Moheb program in 2012 (for case group) should not have any history of serious mental illness (like bipolar or schizophrenia) and be at least 13 years old. In the control group, the people who have participated in other trainings and social-based programs were excluded from the study.

The measuring instruments consisted of a local preparedness checklist and questionnaire as follows:

1) A demographic questionnaire which collected the information about the gender, age, marital status, education, occupation, average monthly income and the participants' cooperation with Welfare organization,

2) A questionnaire of effectiveness evaluation of Moheb project in local communities. Because of lack of a reliable test for assessing the effectiveness of reengineering process and the reaction of the people in the society, at first, a reengineering effectiveness evaluation questionnaire was prepared and evaluated based on educational norms and objectives of Moheb reengineering project. Then, to determine the reliability of the questionnaire, among the provinces in which no social-based programs were executed, Alborz Province (Karaj City, upper Hesarak section, and the colony region of Masjed Jeme') was selected as the pilot region. This pilot study was performed at two stages. After reviewing the questions in first stage, the Cronbach $\alpha$ coefficient in the second stage was found 0.0704 . After two stages, 17 questions were obtained according to Table 1, with subscales of the disaster management knowledge, disaster management attitude, and the individual performances and behaviors in the face of disasters.

3) Preparedness checklist on respond capacity of the local people: the checklist was prepared according to specialists ideas and was tested in the second stage of Alborz Province pilot study. To increase the test credibility, the checklist was completed by a rater after close observation of the conditions and preparedness of local communities with regard to the presented items and based on documentations and evidence. Four conditions were presupposed for each item in this checklists: prepared $(+)$, not prepared (-), somehow prepared $(\sim)$ and undecided or unable to evaluate (?). It is to be noted that with regard to the importance of each item in the checklist in determining the degree of preparedness, the importance coefficient of 1 to 5 was considered for each item. The rating for each item was calculated according to the collective ideas of the specialists in the field. Each item was given four status of "have" (2 points), "somehow" (1 point), "did not have" ( 0 points $)$ and "undetermined" ( 0.5 points $)$. The number of items in this checklist was 14 .

After designing and reliability evaluation of the study instruments, the researchers administered the questionnaires in 4 local communities of the case group which were Lathar (Isfahan Province) Fathabad (Fars Province), Golshahr (Hormozgan Province), Rahamtabad (South Khorasan) and 4 local communities of the control group including Marandiz (Khorasan Razavi Province), Amrabad (Tehran Province), Ali-ibn-Abitaleb Mosque neighborhood (Markazi Province), and Kohanabad (Semnan Province). The questionnaires were administered individually and if it was needed, the questionnaire was read to the participant and the responses were recorded. Completing the questionnaire took 30 to 45 minutes.

SPSS-20 was used for data description and analysis. Descriptive methods included average and standard deviation, frequency and percentage. The inferential meth-

Table 1. Different sections of effectiveness evaluation questionnaire.

\begin{tabular}{|c|c|c|c|}
\hline Domain & Questions & Explanations & Range of Marks \\
\hline Knowledge & 1 to 7 & Multiple choice questions (three wrong answers and one correct) & 0 to 7 \\
\hline Attitude & 8 to 12 & Four answer questions (from ‘I totally agree' to 'I don't know’) & 0 to 15 \\
\hline Performance & 13 to 17 & Three answer questions (yes, somehow, no) & 0 to 15 \\
\hline
\end{tabular}


ods included two independent samples t test and analysis of variance for normal variables and the Chi-square, Mann-Whitney and Kruskal-Wallis tests for non-normal variables, also Kolmogorov-Smirnov test was used for determining normality of data values.

\section{Results}

A total of 390 people participated in this research and among them 222(56.9\%) lived in local communities of the case provinces, and $168(43.1 \%)$ in control provinces.

Average scores of knowledge, attitude, and performance of the participants in two groups of case and control are presented in Table 2.

Average preparedness score in each of studied local communities, separated in two groups of case and control are presented in Table 3.

To investigate the normality in data values of knowledge, attitude, and performance, the KolmogorovSmirnov test was carried out. The results indicated that the scores obtained for these three variables were not normally distributed. Therefore, to compare the scores of knowledge, attitude, and performance of the people in both groups of case and control, Mann-Whitney test was applied. According to the results, the attitude of participants in case provinces were significantly better than the attitude of people in control provinces. Also, the performance of individuals in case provinces was significantly better than the performance of individuals in control provinces. The results of the test are presented in Table 4.

Due to non-normality of knowledge, attitude, and performance scores, non-parameter test of Kruskal-Wallis was applied for comparing them. Average rank of knowledge, attitude, and performance marks, separated into age groups and also the results of Kruskal-Wallis test are presented in Table 5. With regard to the obtained results, the age group of 30-49 years had the highest ranking average in knowledge area. However, the knowledge of people in the child group does not show a significant difference $(\mathrm{P}=0.428)$. In attitude area, child group does not show a significant difference, too $(\mathrm{P}=0.311)$. Also, based

Table 2. Average knowledge mark in case and control provinces.

\begin{tabular}{|c|c|c|}
\hline Subscale & Groups & Average \\
\hline \multirow{2}{*}{ Knowledge } & Case & 4.676 \\
\hline & Control & 4.315 \\
\hline \multirow{2}{*}{ Attitude } & Case & 10.81 \\
\hline & Control & 10.188 \\
\hline \multirow{2}{*}{ Performance } & Case & 10.028 \\
\hline & Control & 8.773 \\
\hline
\end{tabular}

Table 3. Preparedness score in local communities.

\begin{tabular}{ccc}
\hline & Province (Local Communities) & Average Score \\
\hline Case & Isfahan (Lathar) & 80.50 \\
& South Khorasan (Kheyrabar) & 46 \\
& Fars (Fathabad) & 85 \\
Hormozgan (Golshahr) & 73.75 \\
Tehran (Amrabad) & 0 \\
Markazi (Ali-ibn-Abitaleb Mosque) & 0 \\
Khorasan Razavi (Marandiz) & 44 \\
Semnen (Kohanabad) & 6 \\
\hline
\end{tabular}


Table 4. Comparison of Mann-Whitney values in case and control provinces.

\begin{tabular}{|c|c|c|c|c|}
\hline Subscales & \multicolumn{2}{|c|}{ Average Rank } & \multirow[t]{2}{*}{ Statistics of the Test ${ }^{\ddagger}$} & \multirow{2}{*}{$\begin{array}{c}\text { P-value } \\
0.019 *\end{array}$} \\
\hline \multirow{3}{*}{ Knowledge } & Case & 164.89 & & \\
\hline & & & 9865.500 & \\
\hline & Control & 141.39 & & \\
\hline \multirow{3}{*}{ Attitude } & Case & 181.93 & & $0.022 *$ \\
\hline & & & 12109.000 & \\
\hline & Control & 157.25 & & \\
\hline \multirow{3}{*}{ Performance } & Case & 203.95 & & $>0.001^{*}$ \\
\hline & & & 11827.500 & \\
\hline & Control & 154.30 & & \\
\hline
\end{tabular}

‡ The statistic of Mann-Whitney test.

Emergencies and |Disasters [Oluarterly

* Significance level at 0.05 .

on these results, the age group of under 19 years have the highest rank in performance area. The 30-49 years old group came into the second place. But even here, the difference was not significant $(\mathrm{P}=0.511)$.

The comparison of knowledge, attitude, and preparedness of participants in local communities are presented in Table 6, with age-separated rank in two groups of case and control. Among the local communities in case provinces, Fars Province had the highest preparedness. Isfahan came into the second and Hormozgan stood in the third place. South Khorasan showed the lowest rank in preparedness. In control provinces, Khorasan Razavi showed the highest level of preparedness and Semnan got the second place. Tehran and Markazi provinces got the lowest marks in preparedness. In order to compare the marks obtained from case and control areas, MannWhitney test was applied which revealed that the aver-

Table 5. Comparison of knowledge, attitude, and preparedness of participants in local communities with respect to different age groups.

\begin{tabular}{cccc}
\hline & & \multicolumn{3}{c}{ Average Rank of Subscales } \\
\cline { 2 - 4 } Age Group, $\mathbf{y}$ & Knowledge & Attitude & Preparedness \\
\cline { 2 - 4 } & 70.31 & 73.17 & 98.53 \\
$20-29$ & 80.33 & 91.30 & 81.25 \\
$30-49$ & 82.83 & 92.93 & 93.63 \\
$50-59$ & 60.13 & 82.53 & 83.96 \\
$\geq 60$ & 69.13 & 72.82 & 84.95 \\
\hline Statistics of the test* & 3.840 & 4.773 & 3.284 \\
\hline P-value & 0.428 & 0.311 & 0.511 \\
\hline
\end{tabular}

*Kruskal-Wallis test was taken.

** Significance level at 0.05.

Table 6. Comparison of case and control local communities.

\begin{tabular}{|c|c|c|c|}
\hline & Average Ranking & Statistics of the Test & P-value \\
\hline Case & 6.50 & & \\
\hline & & $<0.001$ & 0.029 \\
\hline Control & 2.50 & & \\
\hline
\end{tabular}

* Significance level at 0.05

Emergencies and |Disasters [Oluarterly 
age rank of preparedness in case areas is significantly better than that in control areas.

\section{Discussion}

The results showed that knowledge, attitude, and performance of the people in case provinces were significantly better than knowledge, attitude, and performance of the participants in control provinces. It should be noted that in many similar studies, only the performance, awareness, and sense of the danger of the local people were investigated. However, in this research, apart from local preparedness, we studied the knowledge, attitude, and performance of the local people, too.

The obtained results in this research agreed with some of previous studies on the effectiveness of training and forming emergency response teams at the level of local communities $[11,12,13,14,15,16,18]$. For example, the final report of Vietnam social-based national project for managing crisis which stated that the attitude and performance of local people changed significantly after training [16]. However, the knowledge and awareness, which are the cognitive components of preparedness, were not investigated for facing the consequences of earthquake. The results in this section were also in consistent with the results obtained in Bangladesh social-based danger management program [13]. In Bangladesh, it was also found (at least in the investigated societies) that knowledge and response power of societies in face of floods and earthquakes increased after trainings. Moreover, executing the project has had a positive impact in these societies and the highest impact was seen in preparedness, knowledge, and awareness of local people. Also, some results obtained by the study of society-based groups in Nepal were consistent with this study results.

Investigation of the differences between men and woman with regard to knowledge, performance, and attitude in the face of consequences of earthquake in this study showed that the scores of men in case provinces were significantly higher than those of women. This result was is in agreement with the results obtained by Zokaifar study, who suggested providing appropriate conditions to involve men into more effective cooperation [19].

The main reason of higher preparedness in local men could be many things such as the level of education and literacy which is higher among men than women, which consequently affects their level of knowledge, attitude, and performance. Another reason could be men's higher presence in the society and their wider social connections (for example men start working at the age of 14 and accordingly being exposed to direct and indirect trainings and information). Generally, it is expected that higher level of knowledge would result in higher level of attitude and finally a better performance. In other words, possessing higher level of information in men compared to women in local communities can naturally be a reason for better attitude and finally better performance; and the obtained results support this fact.

The obtained results from comparing the variables of knowledge, attitude, and performance in different age groups indicate that people in the age range of 30-49 years possess the highest average rank of knowledge and attitude. However, the knowledge of individuals in children age group does not have a significant difference. The important point in these results is that although the results show better marks for 30-49 years old group with regard to knowledge and attitude, in 13-19 years old age group, which are the teenagers, better behavioral effectiveness is observed. The best explanation for this difference is that training, reinforcing, and generally investing in teenagers' age group to prepare them for facing disasters can have better behavioral effectiveness compared to adults. Although adults can benefit more through briefing and trainings and improving their knowledge, and even somehow become expert in the field and possess the discrimination power, the behavioral changes in adults compared to teenagers are slower, harder, and more fragile.

Based on the scores obtained from preparedness checklist in case and control areas, the average ranking of preparedness in local communities of studied provinces are significantly higher than preparedness level of the local communities in control provinces. These findings indicate that constructing, briefing, training, and exercising measures in reengineered Moheb project were effective in all project subscales. Accordingly, the level of knowledge, attitude, and performance of the people in local communities about earthquake has improved. Therefore, the preventive measures, and especially training and project promotion, was effective according to the results of this research. Because preparedness means planning for the worst case scenario, paying attention to structural and social infrastructures, vulnerability of low income groups, and finally lessening the suffering of people in local communities demonstrates the role of preparedness in managing crisis to control economic and human casualties.

\section{Conclusion}

Generally, the results of this study showed that promoting and reengineering interventions and sociopsychological supports in disasters (Moheb project) can increase 
three elements of knowledge, attitude, and performance through training and executing maneuvers in local communities, therefore increase the level of social preparedness in the face of probable crises. Furthermore, the results of this study revealed that gender differences should be considered in training content and educational needs of the people. Thus, first of all, the educational needs of women and children in local communities should be evaluated based on their specific needs and then, their educational needs are compiled and presented. The same principle goes with other age groups. Therefore, it is suggested that the trainings and consequently, responsibilities of different members of emergency teams in local communities be determined with regard to different age groups. Concerning these issues, it would be possible to improve the cooperation level of both sexes and different age groups in managing society-based crisis.

\section{Acknowledgments}

The researchers would like to thank all respected authorities and individuals who helped in this study, especially the Chairman of Addiction Prevention and Treatment Improvement Center, Vice-President of Consulting and Psychiatric issues, and all the working and retired specialists in Moheb project in national Welfare Organization and its administrations in provinces and all selected cities. We, especially thank the people of local communities who bestowed their ideas to the researchers in the process of investigating the project effectiveness.

\section{Conflict of Interest}

The authors declared no conflict of interests.

\section{References}

[1] Dash S. Post-Disaster Psychosocial Support: A framework from lessons learnt through pragrammesin South-Asia. The Australasian Journal of Disaster and Trauma Studies. 2009; $1: 1-5$.

[2] Jahangiri K, Tabibi S, Maleki MR, Alamdari S. [A comparative study on community-based disaster management (CBDM) in selected countries and proposing a model for Iran (Persian)]. Payesh. 2008; 8(1):49-57.

[3] Falk K. Preparing for disaster: A community-based approach. $1^{\text {st }}$ ed. Manila: Philippine National Red Cross; 2005.

[4] Pender JS. Climate change, its impacts and possible community-based responses in Bangladesh. Bangladesh: Church of Bangladesh; 2010.
[5] Noparast Z, Mirbeigi M, Moslehi. The role of human structure in disaster the evaluation of empowerment education of the people. Paper presented at: The $4^{\text {th }}$ International Conference on Seismic Retrofitting; 2012 May 2; Tabriz, Iran.

[6] Moslehi M. [Design consulting services and psychosocial support in natural disasters (Persian)]. Tehran: Prevention Bureau of Welfare Organization; 2007.

[7] Hansen P. Psychosocial interventions: A handbook. Copenhagen: International Federation Reference Centre; 2008

[8] Welfare Organization. [Report of maneuver reengineering and modernization projects maneuver psychosocial support in disaster in Ardebil (Persian)]. Tehran: Welfare Organization Publication; 2014

[9] Prevention Development Center, Department of counseling and psychological Affairs. [The guide to Moheb project (Persian)]. Tehran: Welfare Organization; 2013.

[10] Saatchi M. [Evaluation process of staff training in organizations (Persian)]. Journal of Public Management. 1989; 6:34-49.

[11] Schreiber M, Gurwitch R. Listen, protect, and connect: Psychological first aid for children and parents. Los Angeles: University of California; 2006

[12] Imelda A, Zubair M. Community based disaster risk management: field practioners' handbook. Pathumthani: Asian Disaster Preparedness Center, 2004.

[13] Casals J. Community based disaster risk management project, Bangladesh. Oxford: Oxfam; 2007.

[14] Rorick MM, White BA. The CSEDR cost-benefit analysis model. Lalitpur: Mercy Corps; 2010

[15] Oxfam Charitable Organization. Pakistan's communitybased disaster risk management and livelihoods program ef fectiveness review full technical report. Oxford: Oxfam Charitable Organization Publication; 2012.

[16] Asian Management \& Development Institute. Joint partnership to support scale up of the national community-based disaster risk management program in vulnerable provinces in Vietnam. Hanoi: Asian Management \& Development Institute; 2013.

[17] Kapucu N. Collaborative emergency management: better community organizing, better public preparedness and response. Disasters. 2008; 32(2):239-62. doi: 10.1111/j.14677717.2008.01037.x

[18] Hossain MD. Women's participation in social change decision: a study of two union parishads in Bangladesh [PhD dissertation]. Bergen: University of Bergen; 2008.

[19] Zokaeefar A, Mirbeigi, S, Eskash HR, Dousti M, Sedaghatpishe A, Shafiei H. Assessment of counseling and psychosocial support maneuvers in natural disasters in Hormozgan Paper presented at: The $3^{\text {rd }}$ World Conference on Psychology and Sociology; 2014 November 6-8; Izmir, Turkey. 
